\title{
Effect of Ni Addition on the Corrosion Resistance of NiTi Alloy Coatings on AISI 316L Substrate Prepared by Laser Cladding
}

\author{
Yuqiang Feng $\mathbb{D}^{\mathbb{C}}$, Zexu Du and Zhengfei $\mathrm{Hu} * \mathbb{D}$ \\ Key Laboratory for R\&D and Application of Metallic Functional Materials, \\ School of Materials Science and Engineering, Tongji University, Shanghai 201804, China; \\ yuqiang_feng@tongji.edu.cn (Y.F.); 1832875@tongji.edu.cn (Z.D.) \\ * Correspondence: huzhengf@tongji.edu.cn; Tel.: +86-21-6958-5265
}

\section{check for}

updates

Citation: Feng, Y.; Du, Z.; Hu, Z. Effect of Ni Addition on the Corrosion Resistance of NiTi Alloy Coatings on AISI 316L Substrate Prepared by Laser Cladding. Coatings 2021, 11, 1139. https://doi.org/ 10.3390/coatings11091139

Received: 31 August 2021

Accepted: 15 September 2021

Published: 19 September 2021

Publisher's Note: MDPI stays neutral with regard to jurisdictional claims in published maps and institutional affiliations.

Copyright: (c) 2021 by the authors. Licensee MDPI, Basel, Switzerland. This article is an open access article distributed under the terms and conditions of the Creative Commons Attribution (CC BY) license (https:/ / creativecommons.org/licenses/by/ $4.0 /)$.

\begin{abstract}
In this paper, an equiatomic NiTi (55NiTi) alloy powder was mixed with pure Ni powder to prepare laser cladding coatings on a $316 \mathrm{~L}$ stainless steel substrate to study the effect of $\mathrm{Ni}$ addition on the microstructure and corrosion resistance of the coatings. The microstructure and phase composition of the coatings were analyzed using a scanning electron microscope (SEM) with configured energy-dispersive spectrometer (EDS) and X-ray diffractometer (XRD). OCP (open-circuit potential), PD (potentiodynamic polarization) and EIS (electrochemical impedance spectroscopy) experiments were conducted by a Gamry electrochemical workstation, and corresponding eroded morphologies were observed to evaluate the coating's anti-corrosion performance. The addition of Ni led to fine and uniform dendrites and dense microstructure under the metallurgical microscope, which were beneficial for the formation of the passive film mainly consisting of titanium dioxide $\left(\mathrm{TiO}_{2}\right)$. The results show that the pitting potential of the $55 \mathrm{NiTi}+5 \mathrm{Ni}$ coating was $0.11 \mathrm{~V}$ nobler than that of the $55 \mathrm{NiTi}$ coating, and the corrosion current density was less than half that of the $55 \mathrm{NiTi}$ coating. The corrosion initiated preferentially at the interfaces of dendrites and inter-dendritic areas, then spread first to dendrites rather than in the inter-dendritic areas.
\end{abstract}

Keywords: laser cladding; NiTi alloy coating; microstructure; corrosion resistance

\section{Introduction}

Near-equiatomic NiTi (also called 55NiTi, with 55 wt.\% Ni) shape memory alloy (SMA) was first discovered by William J. Buehler in the late 1950s. It can exhibit B2 austenite phase, B19' martensite phase and rhombohedral R-phase based on different thermal or mechanical conditions [1-3]. The thermoelastic martensite transformation of NiTi alloy between the abovementioned phases causes the shape memory effect and its superelasticity, which lead to its wide used in aerospace, navigation, medicine and other fields for applications such as antennas, connectors, stents, actuators, orthodontic arch wires, spectacle frames and so on [4-6]. However, the outstanding properties of this alloy, such as high strength, high ductility and high damping properties, also make it difficult to work with $[7,8]$. As machining and forming the bulk NiTi alloy is a difficult and costly process, the application of NiTi alloy as raw material for surface coating is popularly considered. Abd EI-Fattah prepared NiTi thin films via magnetron sputtering on different substrates and found that crystalline structures were obtained on stainless-steel substrate [9]. Samal et al. investigated thermal-plasma-sprayed NiTi coatings on AISI 304 substrate and found intermetallic phases like $\mathrm{NiTi}_{2}, \mathrm{Ni}_{3} \mathrm{Ti}$ and $\mathrm{Ni}_{4} \mathrm{Ti}_{3}$ [10]. Methods such as electron beam melting (EBM), atomic layer deposition (ALD), plasma immersion ion implantation (PIII) and high-velocity oxygen-fuel (HVOF) are also applied to fabricate NiTi coatings, but none of these processes are widely commercialized in consideration of their cost and inconvenience [11-14].

Laser cladding possesses advantages including controllable thickness, fine microstructure and superior metallurgical bonding of the coating, and has recently seen universal 
use in industry for the production of protective coatings to improve the surface hardness, wear and corrosion resistance and other properties of components $[15,16]$. For example, Norhafzan et al. cladded NiTi coatings on tool steel, and the highest surface hardness was almost three times that of the substrate [17]. Chiu et al. reported that the cavitation erosion resistance of a modified layer with a NiTi coating could reach about 29 times that of the 316L stainless steel substrate [18]. Moreover, how to further improve the performance of NiTi coatings with additives has become a research hotspot. Fu et al. studied the influence of $\mathrm{Cu}$ addition into NiTi coatings; the surface hardness was twice that of the substrate and the wear mass loss in a friction test was reduced by nearly 50\% [19]. Lepule et al. researched the addition of $\mathrm{ZrO}_{2}$ into NiTi coatings, and revealed that the surface hardness and corrosion resistance were significantly improved [20]. Vokoun et al. studied the effect of $\mathrm{Al}_{2} \mathrm{O}_{3}$ and $\mathrm{Pt}$ addition for the surface modification of NiTi films and found that the addition caused non-significant grain size growth and an increase of the martensite transformation temperature by $14^{\circ} \mathrm{C}$ [12].

However, the effect of $\mathrm{Ni}$ itself as an additive on NiTi coating has not yet been studied. According to the Ni-Ti binary phase diagram, as temperature increases above $630{ }^{\circ} \mathrm{C}$, equiatomic NiTi can dissolve more Ni into the matrix [21]. A solutionized single 60NiTi ( $60 \mathrm{wt} . \% \mathrm{Ni}$ ) phase will be formed when heating above $1050{ }^{\circ} \mathrm{C}$ [22]. Khanlari et al. did a great deal of research on $60 \mathrm{NiTi}$ alloy and proved its superior mechanical properties and corrosion resistance in comparison to $55 \mathrm{NiTi}$, which lacks proper dimensional and microstructural stability due to its shape memory effect and is therefore not suitable for precision mechanical or load-bearing applications $[6,23]$. Hence, it is reasonable to speculate that, with increasing Ni content, the performance of 55NiTi coatings could be further improved as well. An innovative solution is applied in our work, using a mixed powder consisting of $55 \mathrm{NiTi}$ powder and an additional $5 \%$ single Ni powder (named $55 \mathrm{NiTi}+5 \mathrm{Ni}$ ) to replace $60 \mathrm{NiTi}$ alloy powder for laser cladding. Since both $55 \mathrm{NiTi}$ alloy powder and Ni powder are commercial (cheaper and easy to obtain), this solution provides great potential to reduce the cost for the preparation of high-performance 60NiTi coatings, which have previously been produced with customized $60 \mathrm{NiTi}$ alloy powder. In our previous research, the effect of $\mathrm{Ni}$ addition on the microstructure and mechanical properties, including microhardness and wear resistance, of the NiTi coating was revealed [24]; in this work, the key aim was to study the effect of $\mathrm{Ni}$ addition on the corrosion resistance of the NiTi coating. The relationship between the microstructure and corrosion resistance of the NiTi coating, the mechanism of the passive film formation and the process of pitting initiation are intensively discussed in this paper.

\section{Experimental Procedure}

\subsection{Material and Specimen Preparation}

Pure Ni powder and 55NiTi alloy powder (99.9\% purity, Jiangsu Willari New Material Technology Co., Ltd., Xuzhou, China) were used as coating materials. The particle sizes were both in the range of 53-106 $\mu \mathrm{m}$, distributed by an automatic dry powder sieving machine by the supplier, and exhibited spherical morphology providing good flowability. The morphologies of the powders are shown in Figure 1. Tables 1 and 2 show the chemical composition of the powders and 316L stainless steel substrate, respectively. 55NiTi powder and single Ni powder were mixed in a weight ratio of 8:1 (to obtain the total weight ratio of $\mathrm{Ni}-\mathrm{Ti}$ at $60 \%: 40 \%$ ) at $250 \mathrm{rpm}$ through a planetary ball mill for $8 \mathrm{~h}$. Prior to laser cladding, the mixed powders were dried at $100{ }^{\circ} \mathrm{C}$ for $1 \mathrm{~h}$, while substrates were polished and ultrasonically cleaned in an acetone bath, and dried in the air. 

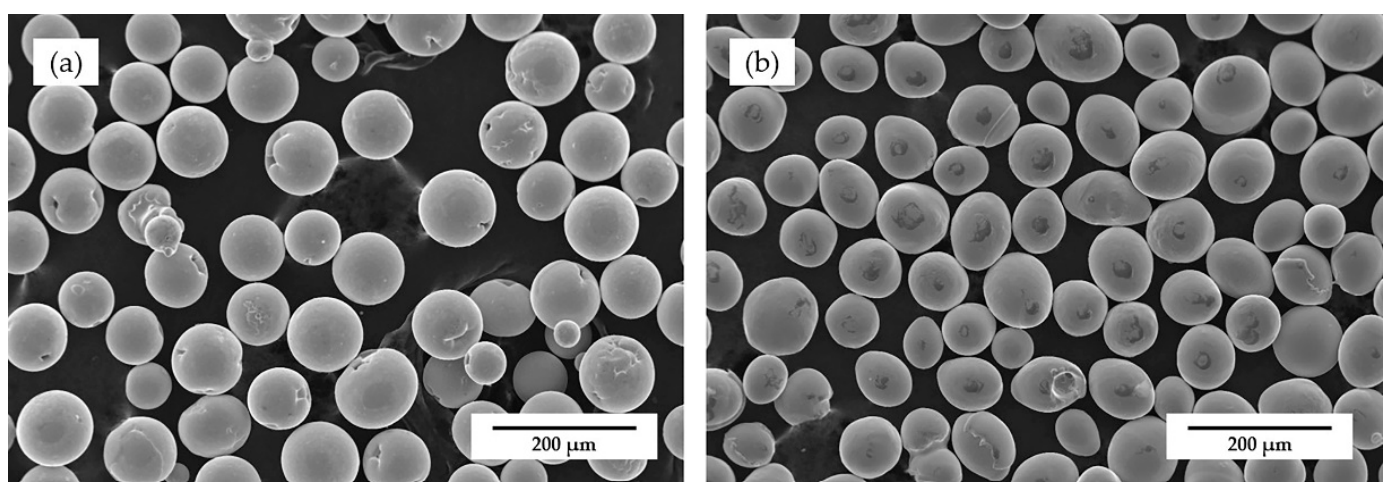

Figure 1. Morphologies of the powders: (a) single Ni powder; (b) 55NiTi alloy powder.

Table 1. Chemical composition of $\mathrm{Ni}$ and 55NiTi alloy powders (wt.\%).

\begin{tabular}{lcccccccc}
\hline Powders & Ni & Ti & Fe & Nb & Co & C & Si & O \\
\hline Pure Ni & Bal. & - & 0.003 & - & 0.020 & 0.020 & 0.003 & 0.006 \\
$55 \mathrm{NiTi}$ & 56.46 & Bal. & 0.005 & 0.010 & 0.005 & 0.005 & - & 0.037 \\
\hline
\end{tabular}

Table 2. Chemical composition of AISI 316L stainless steel substrate (wt.\%).

\begin{tabular}{ccccccccc}
\hline Fe & Cr & Ni & Mo & Mn & Si & P & C & S \\
\hline Bal. & 16.32 & 10.12 & 2.04 & 0.92 & 0.34 & 0.026 & 0.016 & 0.015 \\
\hline
\end{tabular}

In the experiment, a high-power fiber laser with a beam wavelength of 1070-1080 nm (YLS-10000, IPG Photonics, Oxford, MA, USA), as shown in Figure 2, was employed for laser cladding. The diameter of the laser beam spot was $0.72 \mathrm{~mm}$. Laser cladding coatings were fabricated on the substrate under the following parameters: $2.0 \mathrm{~kW}$ power, $2 \mathrm{~mm} / \mathrm{s}$ laser scanning speed and $50 \mathrm{rpm}$ powder feeding rate. High-purity argon with a flow rate of $5 \mathrm{~L} / \mathrm{min}$ was used as shielding gas to prevent the oxidation of molten metals. Apart from that, argon was also used as a powder feeding gas with an $8 \mathrm{~L} / \mathrm{min}$ flow rate. The offset distance of the laser track was $0.4 \mathrm{~mm}$, hence, the overlap ratio for multi-track cladding was fixed at about $55 \%$. The processing parameters used were optimized based on our preliminary research $[24,25]$. Substrates were placed on the working stage with heating function and then heated to $250{ }^{\circ} \mathrm{C}$ to release the internal stress before cladding.

After the cladding process, the specimens were cut along the direction transverse to the laser scanning direction with a size of $10 \mathrm{~mm} \times 10 \mathrm{~mm} \times 10 \mathrm{~mm}$. Specimens for microstructure analysis were etched with an acid liquid ( $\left.\mathrm{HF}-\mathrm{HNO}_{3}-\mathrm{H}_{2} \mathrm{O}=1: 4: 5\right)$ after grinding and polishing. The microstructure of the coating was observed through an optical microscope (GX51, Olympus, Tokyo, Japan) and scanning electron microscope (SEM, Zeiss Gemini 300, Oberkochen, Germany). Meanwhile, energy-dispersive spectroscopy (EDS, OXFORD Xplore, Oxford, England) and X-ray diffraction (XRD, Bruker D8 ADVANCE, Karlsruhe, Germany) at a scanning speed of $10^{\circ} / \mathrm{min}$ (range $10^{\circ}$ to $80^{\circ}, \mathrm{Cu} \mathrm{K} \alpha$ radiation at $40 \mathrm{kV}$ and $40 \mathrm{~mA}$ ) were used to study the phase composition. Specimens for the electrochemical experiment were connected to a leading copper wire from the back side and sealed with epoxy resin, leaving an exposed working area of $1.0 \mathrm{~cm}^{2}(10 \mathrm{~mm} \times 10 \mathrm{~mm})$. Then, specimens were polished with emery paper (grade 1000-1500-2000), cleaned in deionized water, rinsed in ethanol and dried before electrochemical testing. 

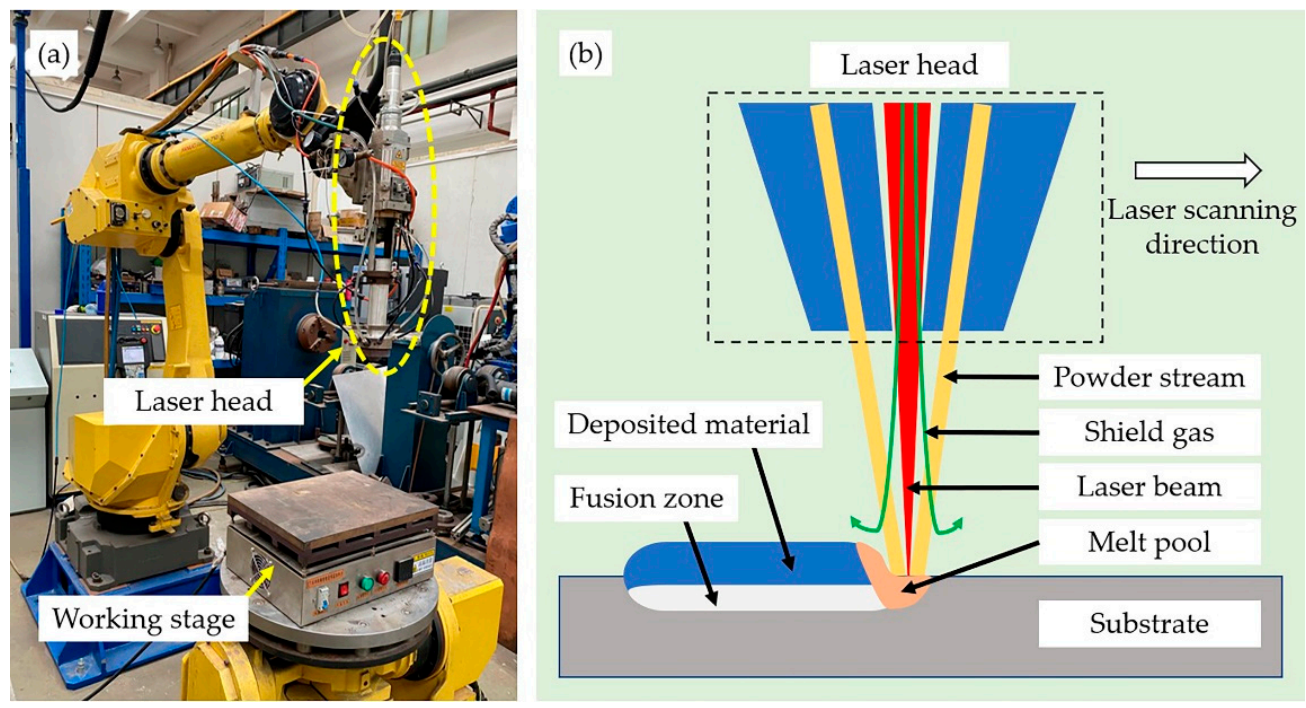

Figure 2. IPG YLS-10000 laser equipment: (a) overview of the equipment; (b) schematic diagram of the laser cladding process.

\subsection{Electrochemical Measurements}

As shown in Figure 3, an electrochemical workstation (Gamry Reference 600+, Gamry, Warminster, PA, USA) with a three-electrode system was employed to conduct the electrochemical experiments. All tests were proceeded in a $3.5 \mathrm{wt} . \% \mathrm{NaCl}$ solution at room temperature. A saturated calomel electrode (SCE) was used as the reference electrode (RE), a platinum electrode was selected as the counter electrode (CE) and the specimen was the working electrode (WE). After $2 \mathrm{~h}$ immersion in the solution to reach a stable potential, the open-circuit potential (OCP) of the anodes was tested. The potentiodynamic polarization (PD) test was conducted in the range of -0.5 to $1.5 \mathrm{~V}$ (vs. OCP potential) with a voltage scanning speed of $0.1 \mathrm{mV} / \mathrm{s}$. The electrochemical impedance spectra (EIS) of the specimens were also measured, with a frequency range from $100 \mathrm{kHz}$ to $0.01 \mathrm{~Hz}$ at an amplitude of $5 \mathrm{mV}$, to evaluate the electrochemical behavior. The parameters for electrochemical tests were chosen according to ASTM standard G3-89 (2010) and ASTM G5-94 (2004), and in consideration of the capability of the Gamry electrochemical workstation on hand. To study the pitting process during the corrosion, the morphology of the cladding samples after corrosion was also observed with the above-mentioned SEM.
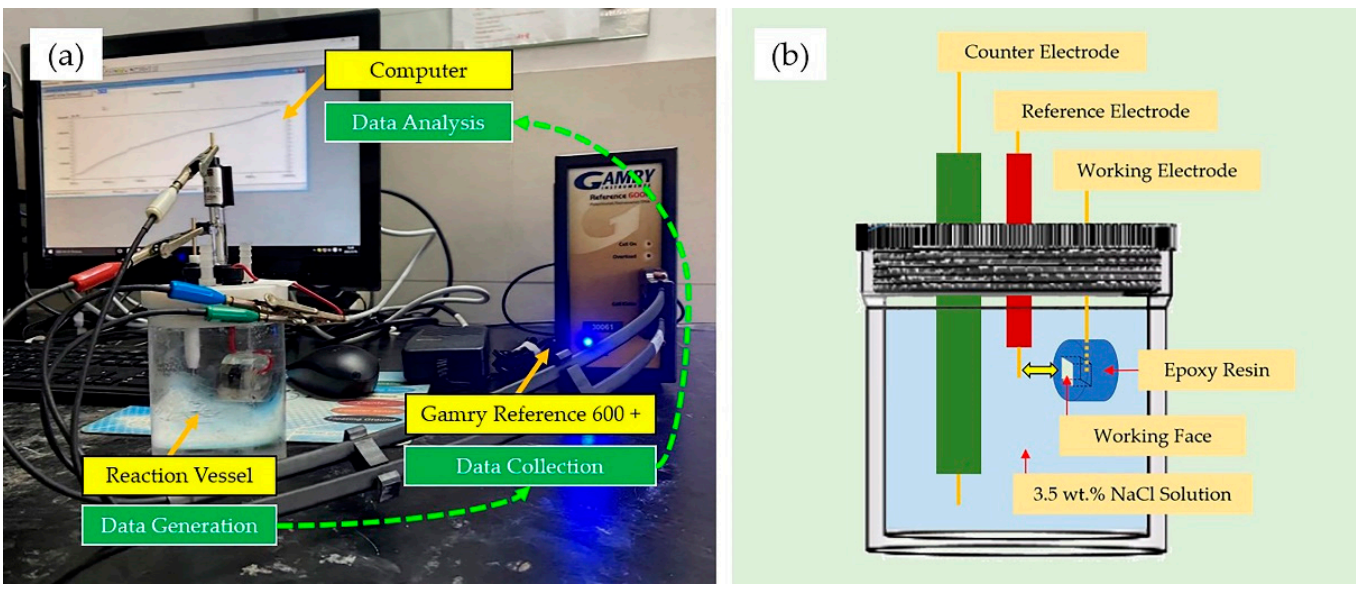

Figure 3. Electrochemical workstation: (a) Gamry Reference 600+; (b) schematic diagram of the three-electrode system. 


\section{Results}

\subsection{Macroscopic Morphology of the Coating}

Figure 4 displays the surface topography of the coatings. The laser cladding tracks on the substrate are obvious and easy to recognize. Some cracks, marked with white arrows in Figures 4 and 5, along the direction perpendicular to the laser scanning path were found on the surface of 55NiTi coating. The formation of these cracks was observed during the cooling stage after the cladding process, which is attributed to the release of the thermal stress caused by the rapid cooling [26]. However, no cracks were found on $55 \mathrm{NiTi}+5 \mathrm{Ni}$ coating, the surface of which was plain and smooth. Figure 5 shows the cross-sectional morphologies of the coatings, and it can be seen that the cracks on the 55NiTi coating surface penetrated the whole cladding layer. However, both coatings formed the expected metallurgical bonding with the substrate. In addition, the fusion line between coating and substrate was more continuous and uniform in the $55 \mathrm{NiTi}+5 \mathrm{Ni}$ coating. Studies have revealed that the phase transition temperature of NiTi alloy decreases with increasing content of $\mathrm{Ni}$ [22]. That is to say, the energy required for its phase transformation is reduced by increasing the content of Ni. With the same amount of heat input, while the coatings were fabricated under the same parameter settings, the phase transformation taking place in the $55 \mathrm{NiTi}+5 \mathrm{Ni}$ coating would be more sufficient and close to thermodynamic equilibrium, which is beneficial to form a steady and uniform microstructure. As a result, the transition zone in the $55 \mathrm{NiTi}+5 \mathrm{Ni}$ coating was also wider than that in the $55 \mathrm{NiTi}$ coating.
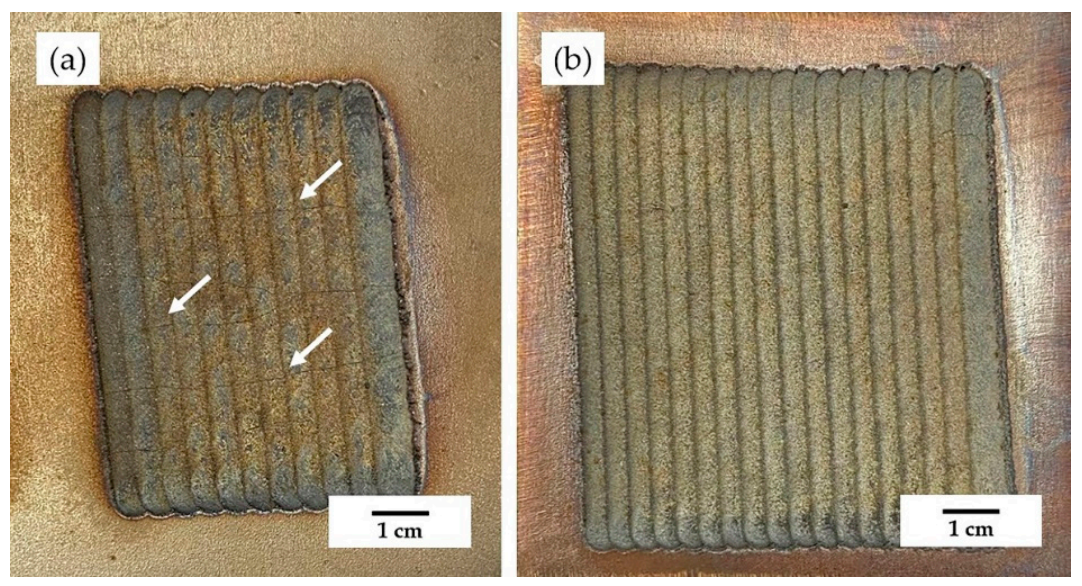

Figure 4. Surface topography of the coatings: (a) 55NiTi coating; (b) $55 \mathrm{NiTi}+5 \mathrm{Ni}$ coating.
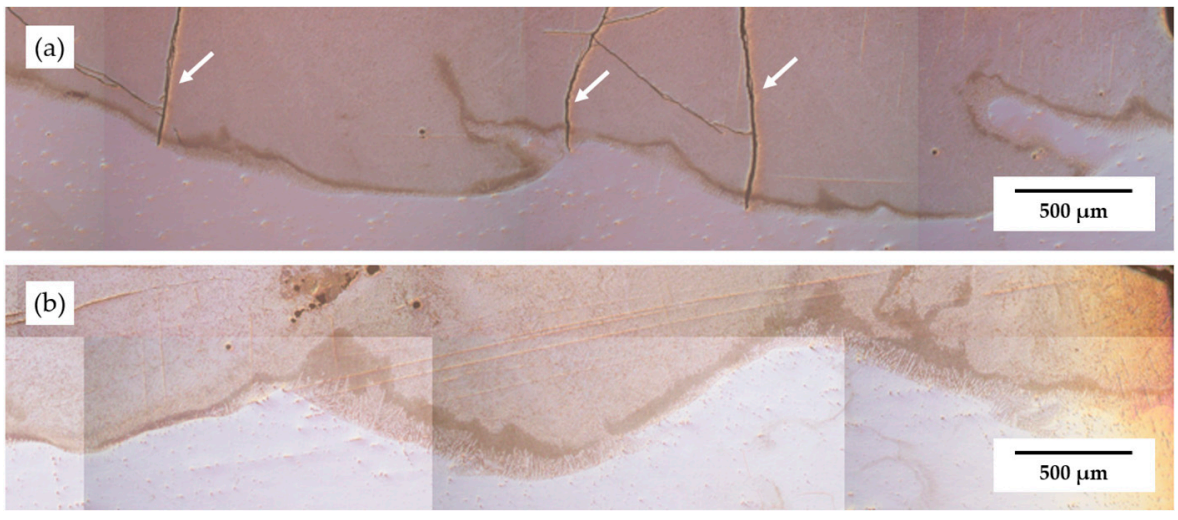

Figure 5. Cross-sectional morphologies of the coatings: (a) 55NiTi coating; (b) 55NiTi $+5 \mathrm{Ni}$ coating.

\subsection{Phase Composition and Microstructure of the Coating}

The XRD patterns of the laser cladding coatings are shown in Figure 6. It can be seen that the coatings were mainly composed of $\mathrm{NiTi}$ and $\mathrm{Ni}_{3} \mathrm{Ti}$ phases, which had the 
strongest diffraction peaks. There were also secondary phases such as $\mathrm{Ni}_{4} \mathrm{Ti}_{3}, \mathrm{NiTi}_{2}$ and $\mathrm{Fe}_{2}$ Ti. It is well known that laser cladding is a quick melting and rapid nonequilibrium solidification process; therefore, multiple phases coexist and some diffraction peaks may overlap each other, even diverging from the equilibrium positions in the cladding layer [27]. For instance, $\mathrm{Ni}_{4} \mathrm{Ti}_{3}$ is a metastable phase with rhombohedral crystal structure precipitated from NiTi phase during the rapid cooling process $[22,28]$, and its diffraction peaks were almost overlapped with that of the NiTi phase. This nanoscale structure is supposed to be decomposed to the stable $\mathrm{Ni}_{3} \mathrm{Ti}$ phase through the precipitation sequence $\mathrm{Ni}_{4} \mathrm{Ti}_{3} \rightarrow$ $\mathrm{Ni}_{3} \mathrm{Ti}_{2} \rightarrow \mathrm{Ni}_{3} \mathrm{Ti}$ during the cooling process [23]. The formation of $\mathrm{Fe}_{2} \mathrm{Ti}$ results from the elemental Fe which is diluted from the substrate into the coating during the melting stage; hence, we believe that the $\mathrm{Fe}_{2} \mathrm{Ti}$ phase mainly existed in the bottom area of the coating. A previous study mentioned that the addition of Ni could suppress the formation of the brittle $\mathrm{Fe}_{2} \mathrm{Ti}$ phase [29]. The $\mathrm{NiTi}_{2}$ phase was only detected in the 55NiTi coating, while a Ti-rich environment is the precondition for the formation of a $\mathrm{NiTi}_{2}$ phase [21]. With the addition of $\mathrm{Ni}$, even if there was a small amount of $\mathrm{NiTi}_{2}$ formed in the $55 \mathrm{NiTi}+5 \mathrm{Ni}$ coating during early phases, it would react with surplus $\mathrm{Ni}$ atoms and transform to NiTi or $\mathrm{Ni}_{3} \mathrm{Ti}$ phase in the end. In addition, $\mathrm{TiO}_{2}$ was observed in both coatings, and is expected to be in the upper area of the coating. When the laser beam is removed, the high-temperature coating surface is directly exposed to the air, and titanium is an element with high chemical activity, which is favorable for the formation of titanium oxide.

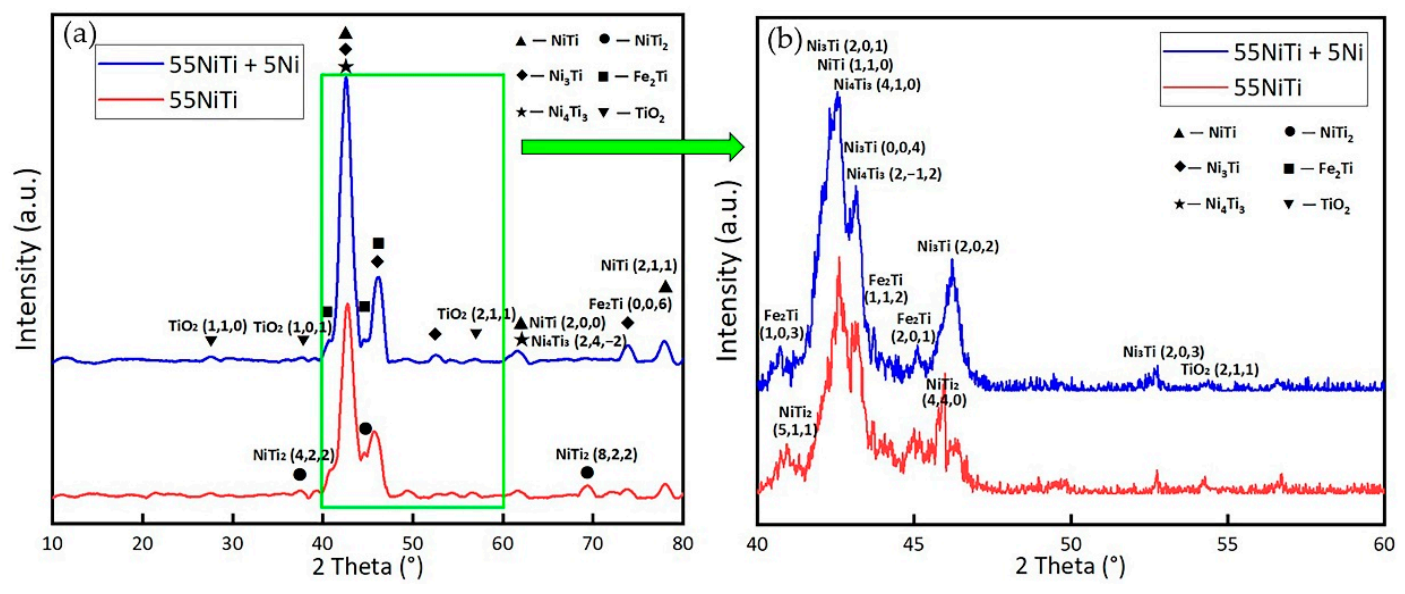

Figure 6. XRD results of the coatings: (a) overview of the patterns; (b) magnification of the patterns between $40^{\circ}$ and $60^{\circ}$.

Figure 7 displays the transition area of the coatings, which is the boundary to the substrate. It can be seen that the width of the transition area of the $55 \mathrm{NiTi}+5 \mathrm{Ni}$ coating was wider than that of the 55NiTi coating, which could be attributed the slight decrease of the transformation temperature caused by $\mathrm{Ni}$ addition. This is supported by reports that the phase transformation temperature of NiTi alloy decreases with the increasing content of $\mathrm{Ni}$ [22]. Comparing Figure $7 \mathrm{c}, \mathrm{d}$, it can be found that the microstructure of the $55 \mathrm{NiTi}+5 \mathrm{Ni}$ coating was much denser than that of the 55NiTi coating due to the smaller grain size. It is well known that the solidification process starts from the bottom area of the coating and then moves upwards. With the addition of extra Ni particles, there are more embryos in the $55 \mathrm{NiTi}+5 \mathrm{Ni}$ coating during the nucleation process- that is to say, the energy allocated to each grain for growth is not sufficient. Figure 8 shows the distribution of the dendrite grain size in the coating; the grain size was measured with the software Image-Pro Plus 6.0. The average grain size in the bottom area in the $55 \mathrm{NiTi}+5 \mathrm{Ni}$ coating was only $3.1 \mu \mathrm{m}$, which is less than half that in the 55NiTi coating. The measured results are in line with the microstructure observed in Figure 7. With the increase of the undercooling degree, the critical nucleation radius decreased while the nucleation ratio increased, which resulted in the finer grain size in the cladding layer during the solidification process [26]. As is 
well known, small grains are beneficial to improve the mechanical properties of materials according to the fine-grain strengthening effect.
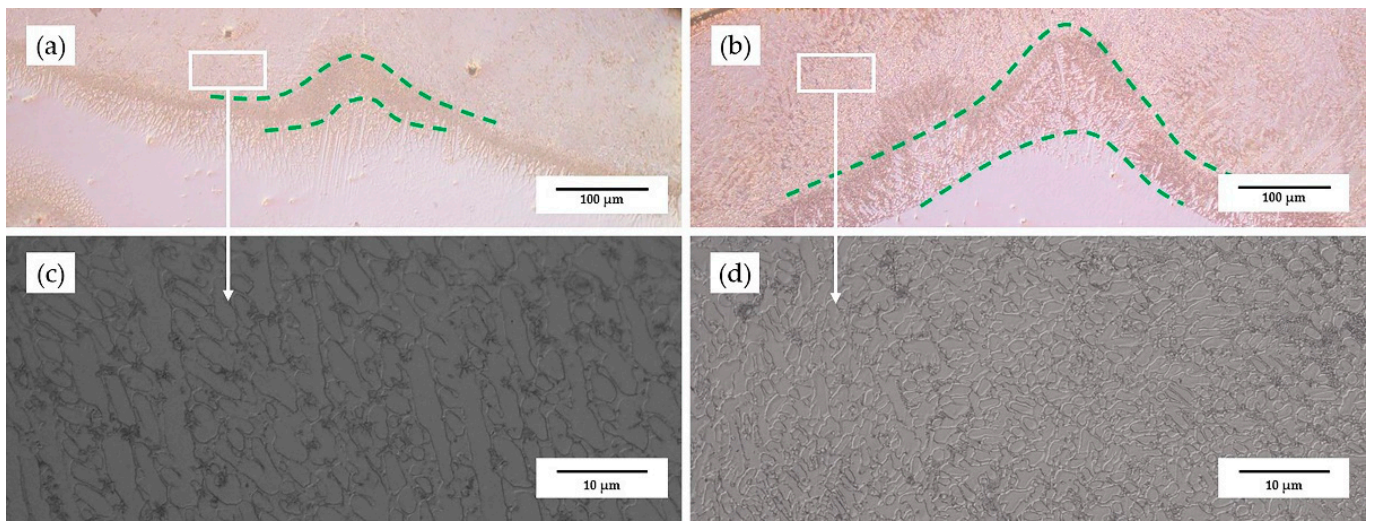

Figure 7. Microstructure of the bottom area in the cladding layer: (a,c) 55NiTi coating; (b,d) $55 \mathrm{NiTi}+5 \mathrm{Ni}$ coating.

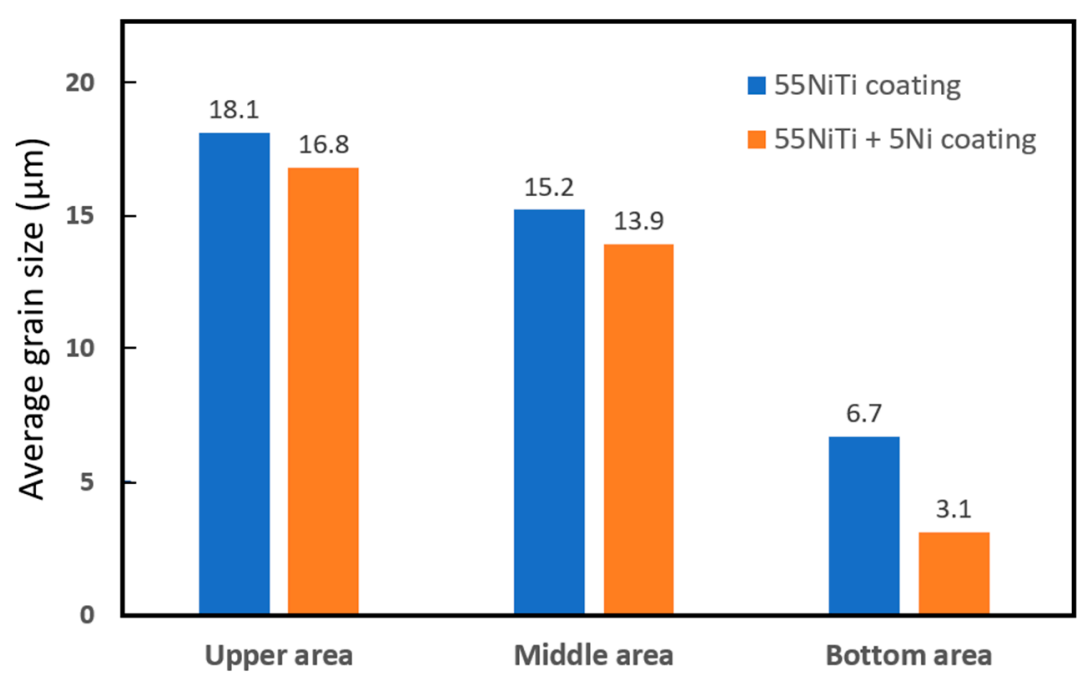

Figure 8. Distribution of the dendrite size in different areas of the coating.

Figure 9 exhibits the microstructure of the upper area of the coating, as upper areas are close to the working surface, and have a significant impact on the coating performance. The average grain size was between 16 and $18 \mu \mathrm{m}$; the $55 \mathrm{NiTi}+5 \mathrm{Ni}$ coating had slightly smaller dendrites than the 55NiTi coating. In addition to the dendrites' and inter-dendrites' structure, there a handful of black particles were also found in the boundary of the dendrites. EDS was used to identify the chemical composition of these phases, and the results of the spectra scan for the marked positions are listed in Table 3. Based on the data of position 1 and position 4 marked in Figure 9, their atomic ratio of $\mathrm{Ni}$ and Ti was close to 1:1, respectively, and it can be concluded that the dendrite structure was NiTi phase. Position 2 and position 5 were rich in $\mathrm{Ni}$, with $\mathrm{Ni}$ - $\mathrm{Ti}$ atomic ratio of almost 3:1; therefore, the inter-dendrite phase can be identified as $\mathrm{Ni}_{3} \mathrm{Ti}$ phase. The black particles in position 3 and position 6 were dominant in $\mathrm{O}$ and Ti; combined with the XRD patterns, this suggests that they are $\mathrm{TiO}_{2}$ phase. $\mathrm{Fe}$ and $\mathrm{Cr}$ atoms, which diffused from the substrate, were on the one hand trapped in the NiTi phase and existed in the form of a solid solution due to the high cooling rate of the laser cladding process; on the other hand, $\mathrm{Fe}$ and $\mathrm{Cr}$ atoms have similar radius and electronegativity to $\mathrm{Ni}$ atom, and could partially replace the $\mathrm{Ni}$ atoms in the B2 structure [30]. 

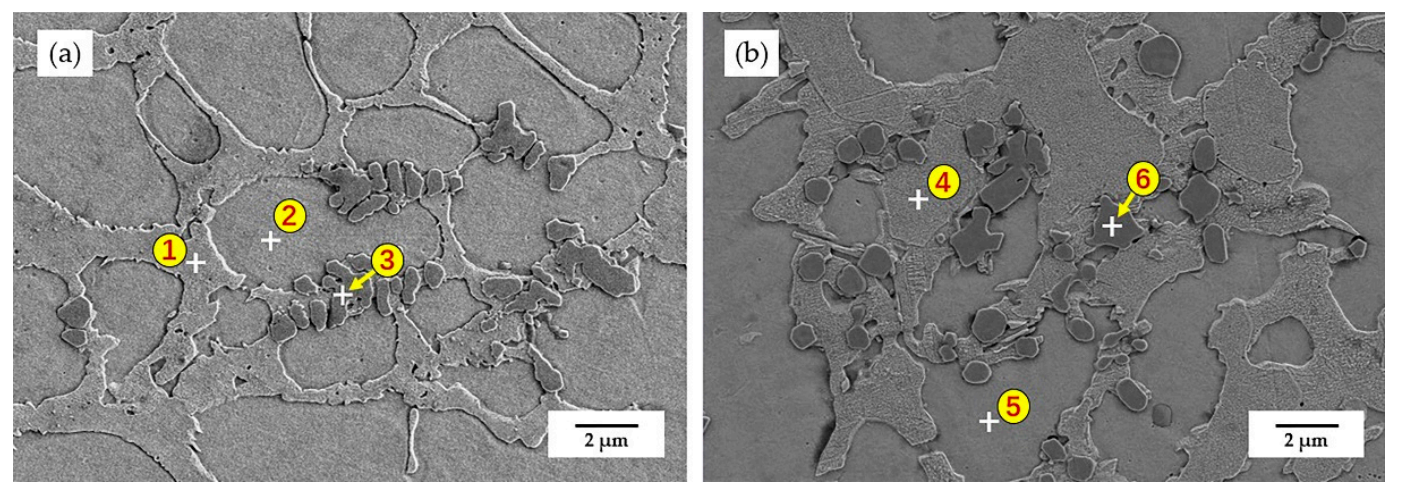

Figure 9. Microstructure of the upper area in the cladding layer: (a) $55 \mathrm{NiTi}$ coating; (b) $55 \mathrm{NiTi}+5 \mathrm{Ni}$ coating.

Table 3. EDS results of spectra scan for the marked positions in Figure 9.

\begin{tabular}{ccccccccc}
\hline Coating & Position & Ni (at.\%) & Ti (at.\%) & Fe (at.\%) & Cr (at.\%) & O (at.\%) & Major Phase \\
\hline \multirow{2}{*}{$55 \mathrm{NiTi}$} & 1 & 31.40 & 32.83 & 17.21 & 10.73 & 7.83 & $\mathrm{NiTi}$ \\
& 2 & 58.12 & 27.45 & 9.40 & 4.12 & 0.91 & $\mathrm{Ni}_{3} \mathrm{Ti}$ & $\mathrm{TiO}_{2}$ \\
\hline \multirow{2}{*}{$55 \mathrm{NiTi}+5 \mathrm{Ni}$} & 3 & 14.72 & 24.54 & 15.21 & 5.41 & 12.40 & 7.75 & $\mathrm{NiTi}$ \\
& 4 & 29.84 & 30.15 & 19.86 & 7.21 & 5.41 & 4.28 & $\mathrm{Ni}_{3} \mathrm{Ti}$ \\
& 6 & 61.82 & 21.28 & 16.46 & 7.48 & 38.78 & $\mathrm{TiO}_{2}$ \\
\hline
\end{tabular}

\subsection{Electrochemical Behavior of the Coating}

\subsubsection{Open-Circuit Potential (OCP) Analysis}

The open-circuit potential (OCP) of the coatings in $3.5 \% \mathrm{NaCl}$ solution for $2 \mathrm{~h}$ was measured, and the changes of the OCP with time are shown in Figure 10. OCP represents the corrosion tendency of a material; a more positive OCP indicates a surface with lower electrochemical activity [31]. The results show that the OCP value increased slowly at the beginning of the immersion but tended to become stable after $60 \mathrm{~min}$ due to the equilibrium of the passive film formation and its dilution [32]. The stabilized OCP values of the specimens are listed in Table 4 . The OCP of the $55 \mathrm{NiTi}+5 \mathrm{Ni}$ coating was about $0.13 \mathrm{~V}$ lower than that of the 55NiTi coating, which means the electrochemical activity of the $55 \mathrm{NiTi}+5 \mathrm{Ni}$ coating was weaker.

\subsubsection{Potentiodynamic Polarization Measurement}

The potentiodynamic polarization measurement was done after the specimens were immersed in a $3.5 \% \mathrm{NaCl}$ solution for $2 \mathrm{~h}$ (i.e., until their OCPs were stable. Figure 11 displays the potentiodynamic polarization results, which show an obvious passivation region for all three curves, indicating that a passive film was formed to protect the surface from corrosion. The corresponding corrosion potential ( $\left.\mathrm{E}_{\mathrm{corr}}\right)$, corrosion current density $\left(\mathrm{I}_{\text {corr }}\right)$ and corrosion rate calculated via Tafel fitting are summarized in Table 5 . The corrosion potential for substrate $316 \mathrm{~L}$ was the highest, at approximately $0.17 \mathrm{~V}$, while those of $55 \mathrm{NiTi}+5 \mathrm{Ni}$ and $55 \mathrm{NiTi}$ coatings were -0.50 and $-0.61 \mathrm{~V}$, respectively. It is clear that the formation of the passive film on the stainless-steel surface was mainly due to chromium $(\mathrm{Cr})$, which has a lower standard electrode potential compared with iron and forms a chromium oxide film to separate the substrate from corrosive solution. However, for $\mathrm{Ni}-\mathrm{Ti}$ based alloys, the excellent corrosion resistance is owing to titanium (Ti), whose standard electrode potential $(-1.63 \mathrm{~V})$ is even lower than chromium $(-0.74 \mathrm{~V})$, and the formed $\mathrm{TiO}_{2}$ film has a strong self-healing ability; once the present oxide film is corroded in the solution, a new $\mathrm{TiO}_{2}$ film will be formed to cover the pitting holes [33-35]. Therefore, the corrosion current densities and corrosion rates of both coatings were much lower than those of the substrate, which is attributed to the strong passivation ability of $\mathrm{TiO}_{2}$ passive film [34]. 


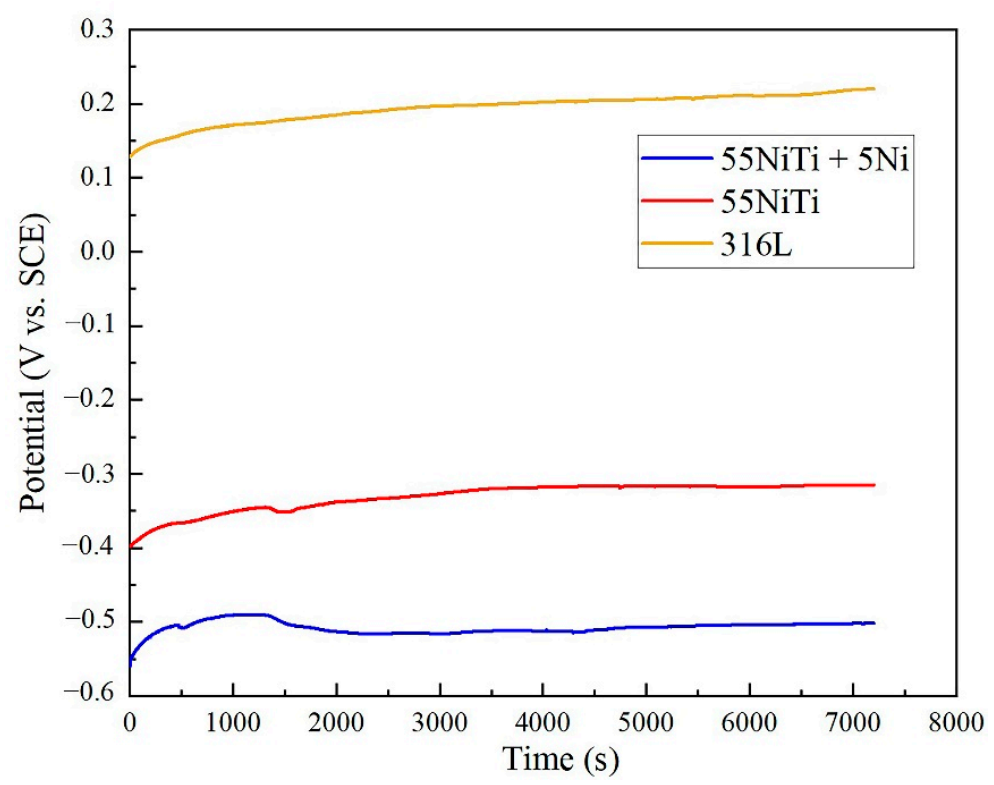

Figure 10. Open-circuit potential (OCP) curves of $2 \mathrm{~h}$ in $3.5 \mathrm{wt} . \% \mathrm{NaCl}$ solution.

Table 4. The stable open-circuit potential of the substrate and coatings.

\begin{tabular}{cccc}
\hline Sample & $\mathbf{5 5 N i T i}+5 \mathbf{N i}$ & $\mathbf{5 5 N i T i}$ & 316L \\
\hline OCP $(\mathrm{V})$ & -0.495 & -0.367 & 0.201 \\
\hline
\end{tabular}

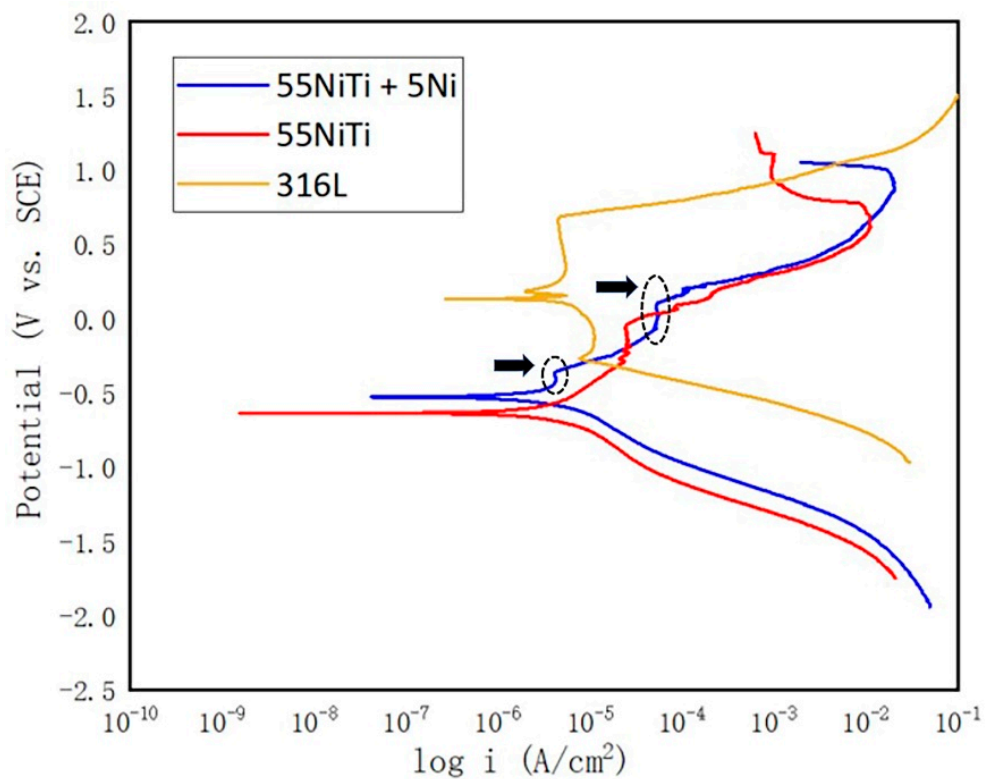

Figure 11. Potentiodynamic polarization behavior of the coatings and substrate.

Table 5. Tafel fitting results of corrosion potential, corrosion current density and corrosion rate.

\begin{tabular}{cccc}
\hline Sample & $\mathbf{E}_{\text {corr }}(\mathbf{V})$ & $\mathbf{I}_{\text {corr }}\left(\mu \mathbf{A} / \mathbf{c m}^{2}\right)$ & $\begin{array}{c}\text { Corrosion Rate } \\
(\mathbf{m p y})\end{array}$ \\
\hline $55 \mathrm{NiTi}+5 \mathrm{Ni}$ & -0.50 & 2.12 & 1.32 \\
$55 \mathrm{NiTi}$ & -0.61 & 5.47 & 3.50 \\
$316 \mathrm{~L}$ & 0.17 & 60.80 & 31.14 \\
\hline
\end{tabular}


Surface morphologies of the specimens after the potentiodynamic polarization tests are displayed in Figure 12. It is obviously that substrate 316L was the most seriously corroded; the diameter of the pitting holes was over $100 \mu \mathrm{m}$. In contrast, the average size of the pitting holes on the coatings was less than $20 \mu \mathrm{m}$, which represents a significant improvement in corrosion resistance compared with the substrate. However, as reported in the literature, NiTi compounds can undergo local corrosion in chloride media [36,37].
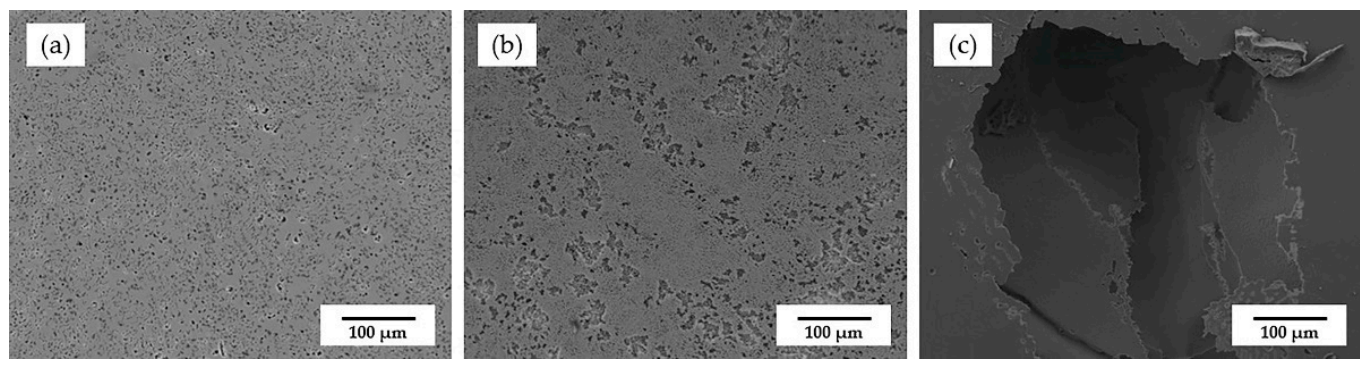

Figure 12. Surface morphology of the samples after a $2 \mathrm{~h}$ potentiodynamic polarization test: (a) $55 \mathrm{NiTi}+5 \mathrm{Ni}$ coating; (b) 55NiTi coating; (c) substrate stainless steel 316L.

Comparing the corrosion performance of the two coatings, both exhibited passivation ability, while the pitting potential of the $55 \mathrm{NiTi}+5 \mathrm{Ni}$ coating was about $0.11 \mathrm{~V}$ nobler than that of the 55NiTi coating, and the corrosion current density and corrosion rate of the $55 \mathrm{NiTi}$ coating were two times larger than those of the $55 \mathrm{NiTi}+5 \mathrm{Ni}$ coating; this is in agreement with the larger size of the pitting holes on the coating. In addition, the two obvious stages marked in the potentiodynamic curve of the $55 \mathrm{NiTi}+5 \mathrm{Ni}$ coating shown in Figure 11 also indicate a stronger self-healing ability and better passivation property. Therefore, it can be speculated that, with the addition of extra $\mathrm{Ni}$, the $55 \mathrm{NiTi}+5 \mathrm{Ni}$ coating had a superior corrosion resistance to the $55 \mathrm{NiTi}$ coating.

\subsubsection{EIS Analysis}

To further analyze the influence of the Ni addition on the corrosion resistance of NiTi coatings, electrochemical impedance spectroscopy (EIS) experiments were conducted in 3.5 wt.\% NaCl solution. The Nyquist plots are shown in Figure 13, which are unfinished capacitance arcs. A bigger diameter of the capacitance arc represents a better coating corrosion resistance, while the Nyquist plots also show the charge transfer resistance in the formed passive film [38]. The results are consistent with the corrosion morphology shown in Figure 12, as fewer pitting holes were found in the $55 \mathrm{NiTi}+5 \mathrm{Ni}$ coating, which is unfavorable for charge transfer.

EIS spectra are usually analyzed with simulation data using a suitable equivalent circuit model. Figure 14 exhibits an equivalent electric circuit (EEC), which is proposed for a deeper analysis of the coatings' electrochemical performance [25,31,39]. In the equivalent circuit, $\mathrm{R}_{\mathrm{s}}$ represents the $3.5 \mathrm{wt} . \% \mathrm{NaCl}$ solution resistance, $\mathrm{R}_{1}$ represents the resistance of the passive film parallel to its constant phase element $\left(C P E_{1}\right), R_{c t}$ represents the charge transfer resistance in parallel with the capacitor $\mathrm{CPE}_{2}$, describing the double-layer chargingdischarging structure. One study showed that $R_{1}$ indicates the stability of the passive film and $R_{c t}$ denotes the charge transfer resistance, which means larger $R_{1}$ and $R_{c t}$ indicate better coating corrosion resistance [40]. CPE is used to replace the capacitor in the circuit to compensate the influence of the surface uniformity of the coatings [41]. The impedance of the CPE is expressed by the formula below:

$$
Z_{\mathrm{CPE}}=\frac{1}{Z_{0}(j \omega)^{n}}
$$

where $\omega$ is the angular frequency ( $1 \mathrm{rad} / \mathrm{s}$ ) defined as $\omega=2 \pi f, f$ is the frequency in $\mathrm{Hz}, j$ is the imaginary number, $Z_{0}$ is the impedance constant and $n(-1 \leq n \leq 1)$ is the experiential exponent of the $\mathrm{CPE}$, which depends on the surface roughness and the 
distribution of the corrosion current density [42]. Usually, a larger value of $n$ means a denser passive film and more uniform current density of the electrode surface. The equivalent components in the EEC were calculated with Gamry Echem Analyst software, and the corresponding fitting values are listed in Table 6 . Results show that the values of $R_{1}, R_{c t}$ and $n$ of the $55 \mathrm{NiTi}+5 \mathrm{Ni}$ coating were all better than those of the $55 \mathrm{NiTi}$ coating, indicating an observable improvement of the corrosion resistance due to the addition of Ni. This result is in consistent with the potentiodynamic polarization test as well. In addition, it can be seen in Figure 13 that the greened dash line, which is the fitting value according to the chosen equivalent circuit, is in good agreement with the experimental results, illustrating that the applied equivalent circuit was able to interpret the electrochemical behavior of the coating and passive film.

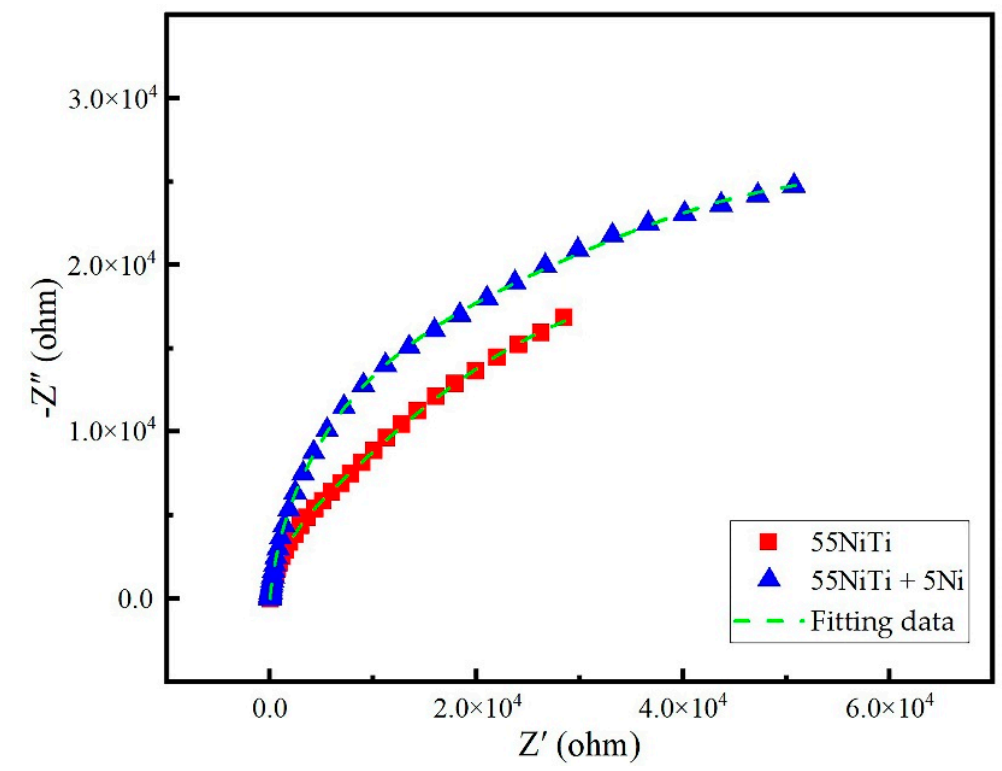

Figure 13. Nyquist plots from the electrochemical impedance spectroscopy (EIS) results of the coatings.

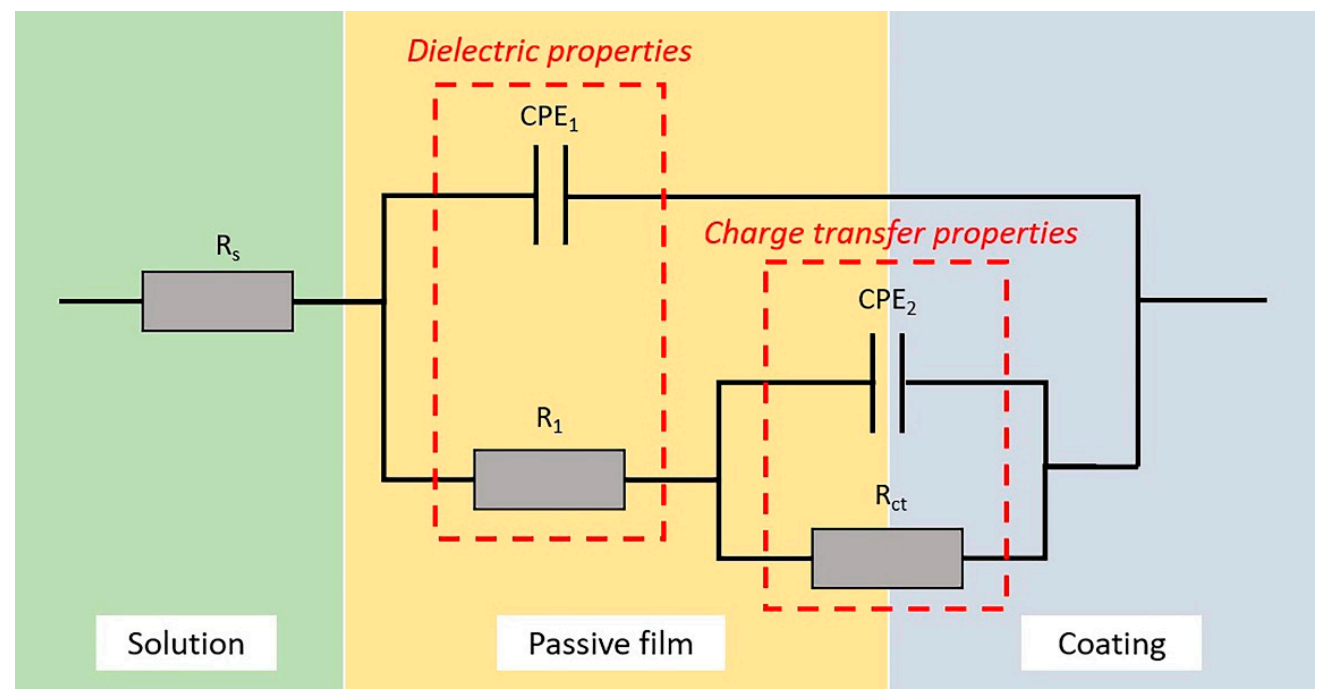

Figure 14. Equivalent electric circuit of the coatings. 
Table 6. Equivalent circuit parameters of the coatings.

\begin{tabular}{|c|c|c|c|c|c|c|c|}
\hline Coatings & $\begin{array}{c}R_{s} \\
\left(\Omega \cdot \mathrm{cm}^{2}\right)\end{array}$ & $\begin{array}{c}R_{1} \\
\left(\Omega \cdot \mathrm{cm}^{2}\right)\end{array}$ & $\begin{array}{c}R_{\mathrm{ct}} \\
\left(\Omega \cdot \mathrm{cm}^{2}\right)\end{array}$ & $\begin{array}{c}\mathrm{CPE}_{1} \\
\left(\Omega^{-1} \cdot \mathrm{cm}^{2} \cdot \mathrm{s}^{\mathrm{n}}\right)\end{array}$ & $n_{1}$ & $\begin{array}{c}\mathrm{CPE}_{2} \\
\left(\Omega^{-1} \cdot \mathrm{cm}^{2} \cdot \mathrm{s}^{\mathrm{n}}\right)\end{array}$ & $n_{2}$ \\
\hline $55 \mathrm{NiTi}$ & 8.40 & $4.12 \times 10^{4}$ & $2.14 \times 10^{5}$ & $3.05 \times 10^{-5}$ & 0.81 & $6.21 \times 10^{-5}$ & 0.88 \\
\hline $55 \mathrm{NiTi}+5 \mathrm{Ni}$ & 10.82 & $7.53 \times 10^{4}$ & $2.35 \times 10^{5}$ & $5.70 \times 10^{-5}$ & 0.97 & $4.86 \times 10^{-5}$ & 0.96 \\
\hline
\end{tabular}

\section{Discussion}

\subsection{The Impact of the Coating Microstructure and Composition on Corrosion Resistance}

Coatings are used to improve the substrate corrosion resistance due to their capability to make the surface inactive or less reactive, usually by forming an oxide film mitigating the corrosion reactions. The outstanding corrosion resistance of NiTi coatings results from the formation of stable and continuous passive films, mainly consisting of titanium dioxide $\left(\mathrm{TiO}_{2}\right)$. According to the previous research from Gaberšček et al. [43], the passive film preferentially grows at active sites such as grain boundaries, dislocations and inclusions. When the energy of the active site exceeds a critical value, the active site will become a nucleation site, where a passive film preferentially starts to form. Passive films can nucleate continuously at these sites and spread to connect with each other until they cover the whole metal surface.

The formation of titanium oxide is influenced by the composition distribution and microstructure of the dendrites and inter-dendric areas in the coating. Figure 15 shows the EDS results of the dendrites and inter-dendritic areas in this study. The dendrites were primarily solidified and the inter-dendritic areas were posteriorly solidified. There was more $\mathrm{Ti}, \mathrm{Fe}$ and $\mathrm{Cr}$; and less $\mathrm{Ni}$ in the inter-dendritic areas. As a result, the passive film was first initiated in the inter-dendritic areas due to the Ti-rich environment, which reacts with $\mathrm{O}$ ions as a nucleation site. Comparing the two coatings, the addition of Ni could suppress the formation of $\mathrm{Fe}_{2} \mathrm{Ti}$ phase during the cooling process, which released more Ti atoms for the formation of a titanium oxide film afterwards [44]. Otherwise, too many precipitates would consume the Ti atom in the coating, resulting in the depletion of $\mathrm{Ti}$ and $\mathrm{Cr}$, which is detrimental to the formation of a passive film. In addition, excessively solidified $\mathrm{Fe}$ and $\mathrm{Cr}$ may cause stacking faults and dislocations, which could offer more nucleation sites and is helpful for the formation of a dense passive film [38].

The above analysis reveals that $\mathrm{Ni}$ addition could promote the formation of uniform and dense dendrites in the cladding layer. In Figure 7 it can be clearly seen that the microstructure of the $55 \mathrm{NiTi}+5 \mathrm{Ni}$ coating was much more compact and denser than that of the 55NiTi coating - that is to say, the distance between the neighboring inter-dendritic areas was also very close. Figure 16 displays the schematic illustration of the passive film initiation and expansion process on the coating surface. When the initial films form at the nucleation sites in the inter-dendritic area, they can quickly start to spread in all directions, reaching and connecting with each other until they cover the entire surface. It was observed that the dendrite size in the $55 \mathrm{NiTi}+5 \mathrm{Ni}$ coating was much smaller than that of the $55 \mathrm{NiTi}$ coating due to the addition of $\mathrm{Ni}$ (Figure 8). A smaller grain size represents more grain boundaries, and grain boundaries play a role as active sites, which are favorable for the nucleation of passive films; therefore, a smaller grain size is also beneficial for generating a thin passivation film. In conclusion, with the addition of $\mathrm{Ni}$, the passive film formed on the $55 \mathrm{NiTi}+5 \mathrm{Ni}$ coating was much more homogeneous and thicker than that on the $55 \mathrm{NiTi}$ coating. 

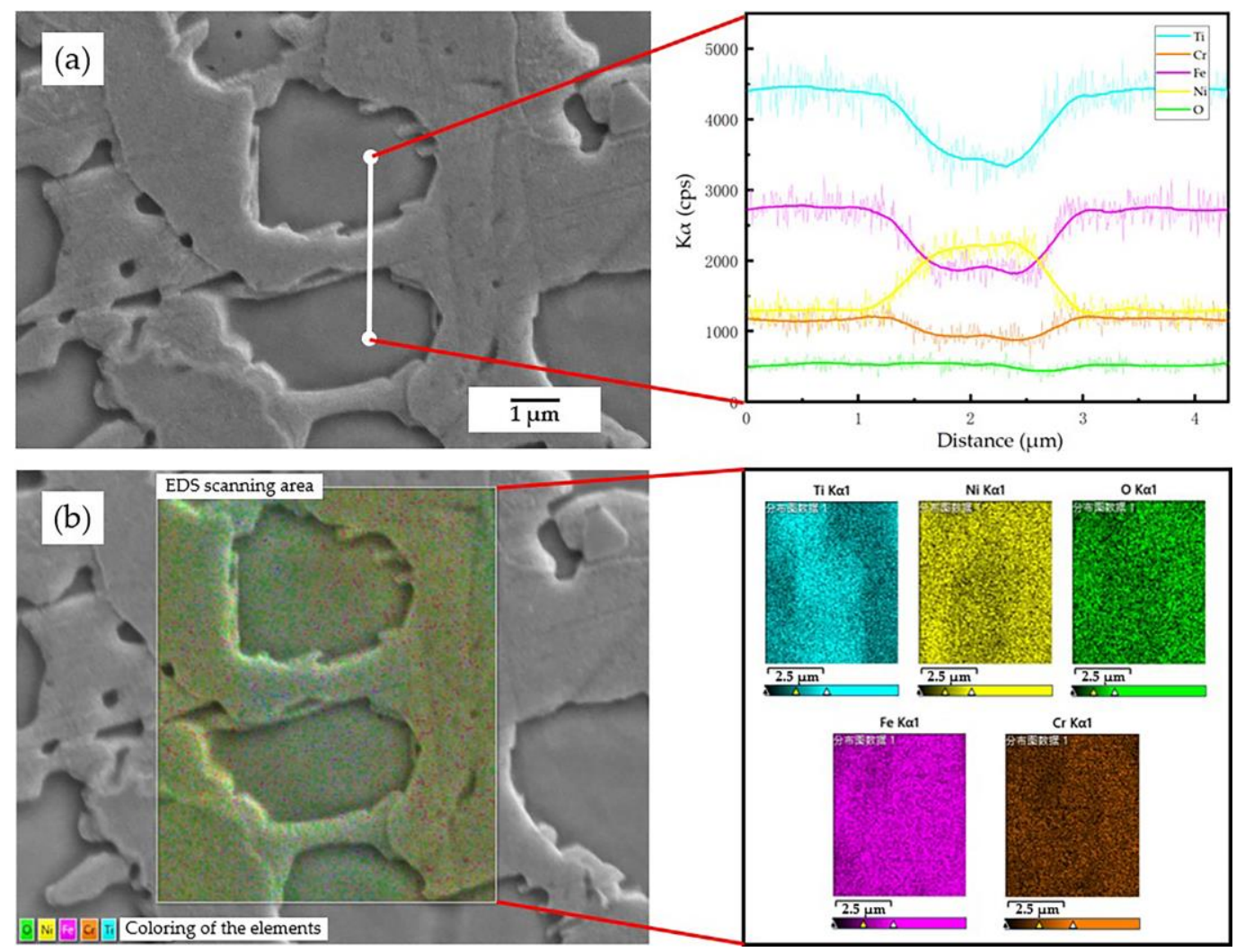

Figure 15. Element distribution in the dendrites and inter-dendritic areas in the $55 \mathrm{NiTi}+5 \mathrm{Ni}$ coating: (a) EDS line scanning results; (b) EDS region scanning results.

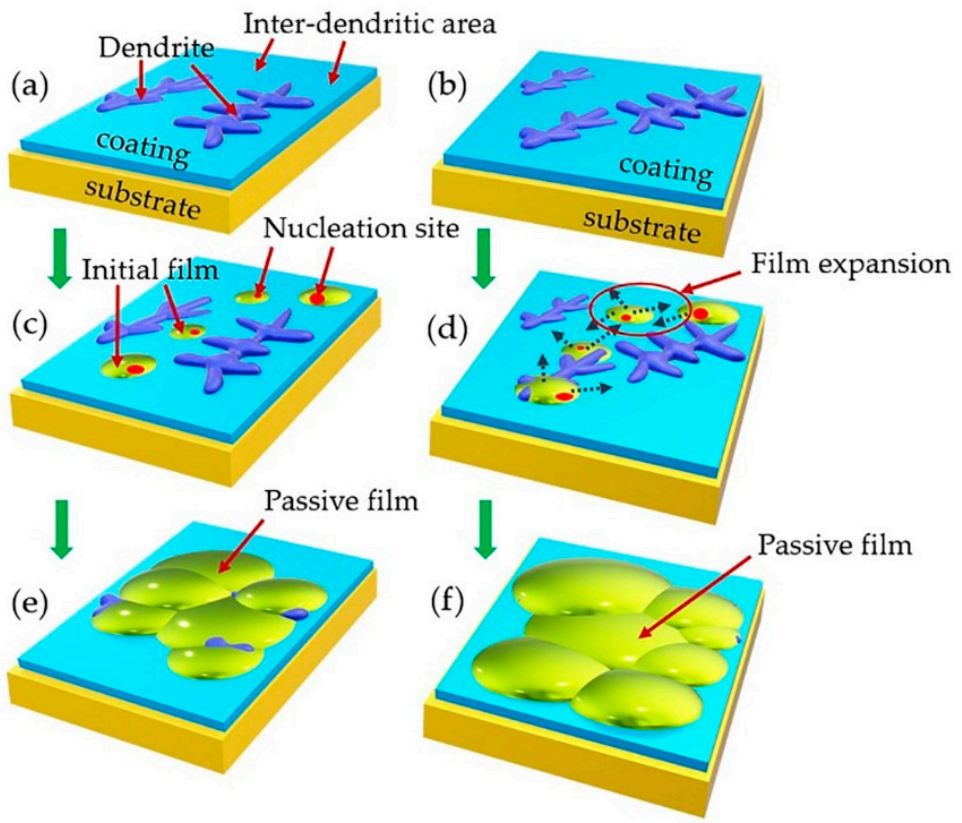

Figure 16. Schematic illustration of the passive film initiation and expansion process: (a,c,e) $55 \mathrm{NiTi}$ coating; (b,d,f) $55 \mathrm{NiTi}+5 \mathrm{Ni}$ coating.

\subsection{Corrosion Initiation and Expansion Process}

It is well known that the occurrence of corrosion is accompanied by the breakdown of the passive film, and usually, the corrosion preferentially occurs at secondary phase precipitates, grain boundaries, inclusions or other heterogeneities and processing defects such as pores and cracks [38]. The presence of these heterogeneities and defect areas 
hinders the formation of a homogeneous and dense passive layer. For instance, as shown in Figure 16e, areas where the passive film is absent or where the passive film is extremely thin, consequently lead to the formation of preferential sites for corrosion. During the pitting initiation process, the destroyed passive film is partially recovered due to the strong repassivation ability of $\mathrm{TiO}_{2}$. However, with the increasing pitting potential, once the equilibrium is broken, the pitting area will expand rapidly.

Figure 17 shows the EDS regional scanning results for the corrosion morphology of the $55 \mathrm{NiTi}$ coating. It is clear that the Ti-rich inter-dendritic area was more or less retained after corrosion. It is also worth noting the bright gray area on the surface of the retained inter-dendritic structure, which was proved to have a high oxygen content based on the EDS results. This area is supposed to be the remaining passive film, which contains titanium oxide. Figure 18 demonstrates an example where the corrosion initiated at the crack area of the coating surface. It can be seen that the corrosion began at the junction of the dendrites and inter-dendritic areas, then the dendrites was eroded preferentially while the inter-dendritic regions remained. As discussed above, Ti content is a key factor that affects the corrosion resistance. There was more titanium in the inter-dendritic region than in the dendrites. A higher titanium content will improve the electrochemical potential, and the potential differences will lead to the preferential erosion of the dendrites.

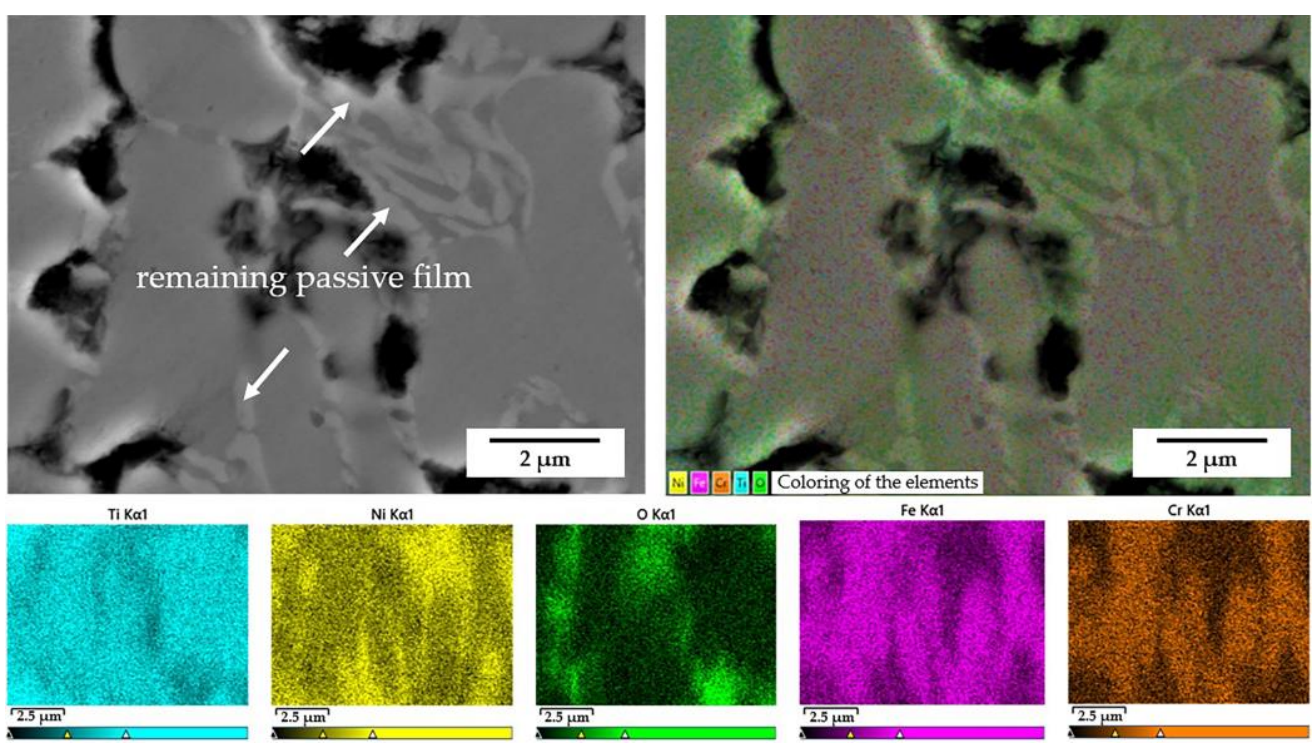

Figure 17. EDS regional scanning results for the 55NiTi coating after corrosion.

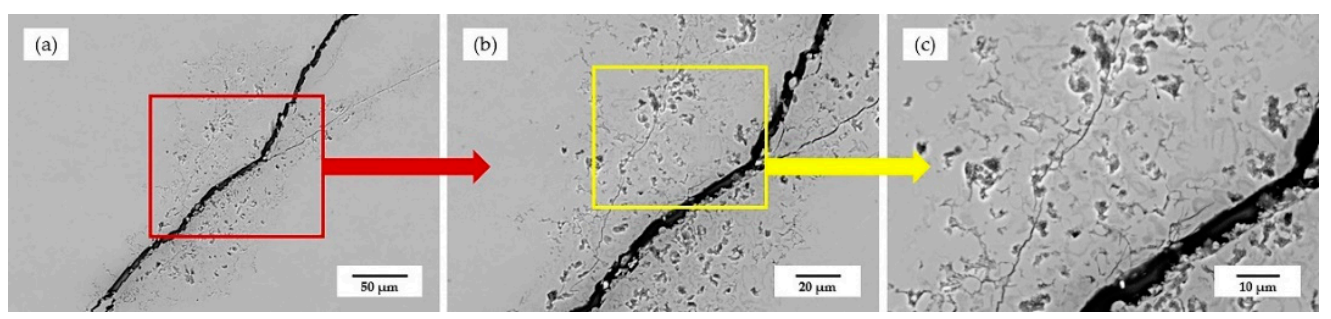

Figure 18. Corrosion morphologies of the 55NiTi coating: (a) full view of the corrosion initiation at a crack area; (b) the middle of the corrosion area; (c) the edge of the corrosion area.

Figure 19 is a schematic illustration of the corrosion expansion process. It can be seen that the initiation and development of the corrosion in the coating is selective. Firstly, the junctions of dendrites and inter-dendritic areas are easily corroded, then the pitting area expands to the dendrites and finally spreads to cover the inter-dendritic areas. 

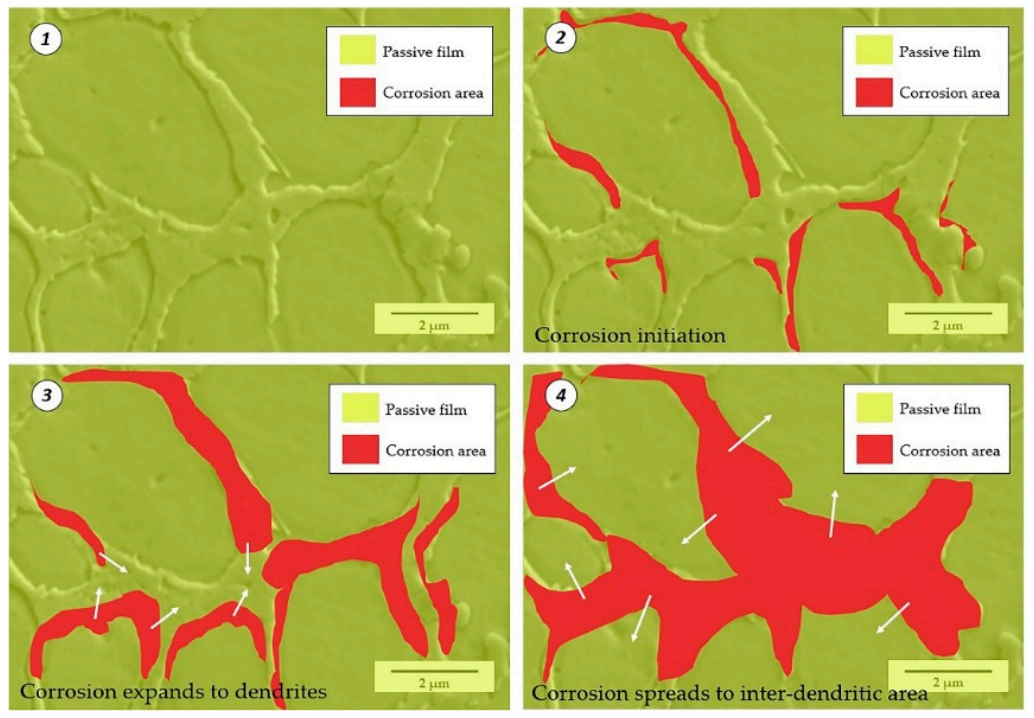

Figure 19. Schematic illustration of the corrosion expansion process.

\subsection{The Impact of Immersion Duration on Corrosion Resistance of the Coating}

The samples were immersed in a $3.5 \mathrm{wt} . \% \mathrm{NaCl}$ solution for 2,5 , and $10 \mathrm{~h}$ to study the effect of immersion duration on the coating corrosion resistance. Figure 20a exhibits the potentiodynamic polarization results of the coatings; the corrosion potential became higher with a longer immersion time in the solution, indicating that the corrosion tendency decreased. It is believed that the passive film on the coating surface would gradually become thicker within a certain time range until the equilibrium was broken. Figure 20b is the Nyquist diagram resulting from the electrochemical impedance spectroscopy (EIS) experiments. The diameter of the capacitance arc increased with as immersion time increased, which means the charge transfer resistance was also increasing. The results reveal that the corrosion resistance of the coatings improved with longer immersion time $(10 \mathrm{~h}>5 \mathrm{~h}>2 \mathrm{~h})$.
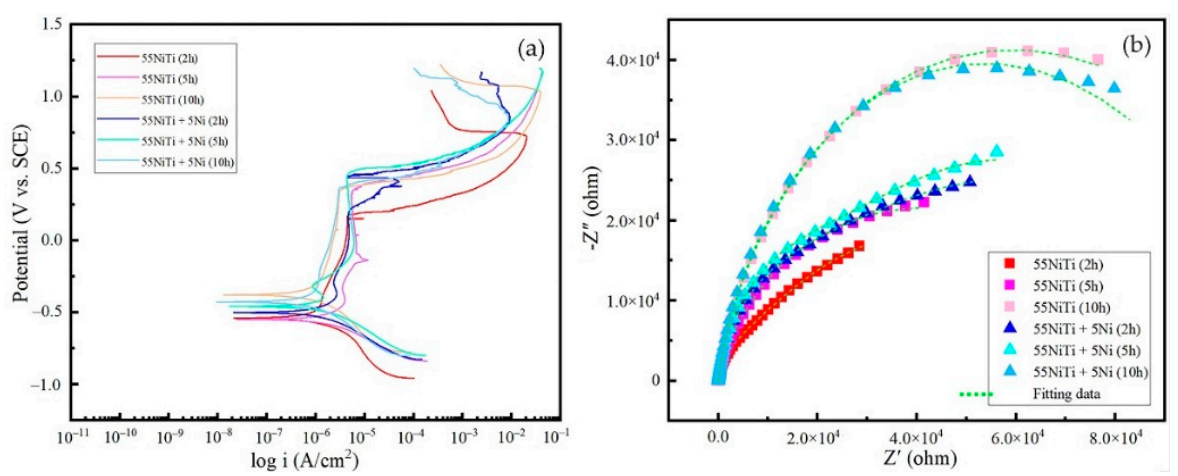

Figure 20. Electrochemical behavior of the coatings under 2,5 and $10 \mathrm{~h}$ immersion in a $3.5 \mathrm{wt} . \% \mathrm{NaCl}$ solution: (a) PD polarization results; (b) Nyquist plots from EIS results.

\section{Conclusions}

This paper investigated the effect of Ni addition on the microstructure and corrosion resistance of NiTi coatings prepared by laser cladding. The relationship between microstructure and corrosion resistance, the mechanism of the passive film formation and the corrosion initiation and expansion process were discussed in detail. The following conclusions can be drawn: 
(1) With the addition of $\mathrm{Ni}$, the microstructure of the coatings became finer and denser; in the bottom area, the average grain size of the $55 \mathrm{NiTi}+5 \mathrm{Ni}$ coating was less than half the grain size of the 55NiTi coating.

(2) The results of electrochemical experiments show that the $55 \mathrm{NiTi}+5 \mathrm{Ni}$ coating had a nobler corrosion potential and smaller corrosion current density, which was due to the homogeneous and thick passive film formed on the surface of the $55 \mathrm{NiTi}+5 \mathrm{Ni}$ coating.

(3) The initiation of the corrosion was selective. It initiated preferentially at the junctions of dendrites and inter-dendritic areas, then spread to the dendrites and finally covered the inter-dendritic areas.

Author Contributions: Conceptualization, Z.H.; methodology, Z.H. and Y.F.; validation, Y.F. and Z.D.; investigation, Y.F. and Z.D.; resources, Z.H.; data curation, Y.F. and Z.D; writing-original draft preparation, Y.F.; writing-review and editing, Z.H. and Y.F.; supervision, Z.H.; funding acquisition, Z.H. All authors have read and agreed to the published version of the manuscript.

Funding: This research was funded by the National Natural Science Foundation of China (51971163).

Institutional Review Board Statement: Not applicable.

Informed Consent Statement: Not applicable.

Data Availability Statement: Not applicable.

Acknowledgments: Author Feng, Yuqiang would like to thank Zhu, Chengnan and Feng, Yulei from Shanghai Jiao Tong University for the support of cladding samples preparation.

Conflicts of Interest: The authors declare no conflict of interest.

\section{References}

1. Otsuka, K.; Ren, X. Physical metallurgy of Ti-Ni-based shape memory alloys. Prog. Mater. Sci. 2005, 50, 511-678. [CrossRef]

2. Buehler, W.J.; Gilfrich, J.V.; Wiley, R.C. Effect of Low-Temperature Phase Changes on the Mechanical Properties of Alloys near Composition TiNi. J. Appl. Phys. 1963, 34, 1475-1477. [CrossRef]

3. Tobushi, H.; Ikai, A.; Yamada, S.; Tanaka, K.; Lexcellent, C. Thermomechanical properties of TiNi shape memory alloy. J. Phys. IV. 1996, 6, 385-393. [CrossRef]

4. Jackson, C.; Wagner, H.; Wasilewski, R. 55-Nitinol-The Alloy with a Memory: It's Physical Metallurgy Properties, and Applications; NASA: Washington, DC, USA, January 1972; p. 5110.

5. Yoneyama, T.; Miyazaki, S. Shape Memory Alloys for Biomedical Applications; Woodhead publishing limited: Cambridge, UK, 2009; p. 101.

6. Khanlari, K.; Ramezani, M.; Kelly, P. 60NiTi: A Review of Recent Research Findings, Potential for Structural and Mechanical Applications, and Areas of Continued Investigations. Trans. Indian Inst. Met. 2017, 71, 781-799. [CrossRef]

7. Saburi, T.; Yoshida, M.; Nenno, S. Deformation behavior of shape memory Ti-Ni alloy crystals. Scr. Metall. 1984, 18, 363-366. [CrossRef]

8. Miyazaki, S.; Kimura, S.; Otsuka, K.; Suzuki, Y. The habit plane and transformation strains associated with the martensitic transformation in Ti-Ni single crystals. Scr. Metall. 1984, 18, 883-888. [CrossRef]

9. Abd El-Fattah, H.A.; El-Mahallawi, I.; Shazly, M.H.; Khalifa, W.A. Microstructure Evolution of NiTi Magnetron Sputtered Thin Film on Different Substrates. Key Eng. Mater. 2020, 835, 68-74. [CrossRef]

10. Samal, S.; Tyc, O.; Cizek, J.; Klecka, J.; Lukáč, F.; Molnárová, O.; de Prado, E.; Weiss, Z.; Kopeček, J.; Heller, L.; et al. Fabrication of Thermal Plasma Sprayed NiTi Coatings Possessing Functional Properties. Coatings 2021, 11, 610. [CrossRef]

11. Pasang, T.; Tavlovich, B.; Yannay, O.; Jackson, B.; Fry, M.; Tao, Y.; Turangi, C.; Wang, J.C.; Jiang, C.P.; Sato, Y.; et al. DirectionallyDependent Mechanical Properties of $\mathrm{Ti}_{6} \mathrm{Al}_{4} \mathrm{~V}$ Manufactured by Electron Beam Melting (EBM) and Selective Laser Melting (SLM). Materials 2021, 14, 603. [CrossRef]

12. Vokoun, D.; Klimša, L.; Vetushka, A.; Duchoň, J.; Racek, J.; Drahokoupil, J.; Kopeček, J.; Yu, Y.-S.; Koothan, N.; Kei, C.-C. $\mathrm{Al}_{2} \mathrm{O}_{3}$ and Pt Atomic Layer Deposition for Surface Modification of NiTi Shape Memory Films. Coatings 2020, 10, 746. [CrossRef]

13. Dai, J.; Liu, Z.; Yu, B.; Ruan, Q.; Chu, P.K. Effects of Ti, Ni, and Dual Ti/Ni Plasma Immersion Ion Implantation on the Corrosion and Wear Properties of Magnesium Alloy. Coatings 2020, 10, 313. [CrossRef]

14. Verdian, M.; Raeissi, K.; Salehi, M. Corrosion performance of HVOF and APS thermally sprayed NiTi intermetallic coatings in $3.5 \% \mathrm{NaCl}$ solution. Corros. Sci. 2010, 52, 1052-1059. [CrossRef]

15. Zhong, M.; Liu, W. Laser surface cladding: The state of the art and challenges. Proc. Inst. Mech. Eng. Part C J. Mech. Eng. Sci. 2010, 224, 1041-1060. [CrossRef]

16. Vilar, R. Laser cladding. J. Laser Appl. 1999, 11, 64-79. [CrossRef] 
17. Norhafzan, B.; Aqida, S.N.; Chikarakara, E.; Brabazon, D. Surface modification of AISI H13 tool steel by laser cladding with NiTi powder. Appl. Phys. A 2016, 122, 348. [CrossRef]

18. Chiu, K.Y.; Cheng, F.T.; Man, H.C. Cavitation erosion resistance of AISI 316L stainless steel laser surface-modified with NiTi. Mater. Sci. Eng. A 2005, 392, 348-358. [CrossRef]

19. Fu, B.; Feng, K.; Li, Z. Study on the effect of $\mathrm{Cu}$ addition on the microstructure and properties of NiTi alloy fabricated by laser cladding. Mater. Lett. 2018, 220, 148-151. [CrossRef]

20. Lepule, M.L.; Obadele, B.A.; Andrews, A.; Olubambi, P.A. Corrosion and wear behaviour of $\mathrm{ZrO}_{2}$ modified NiTi coatings on AISI 316 stainless steel. Surf. Coat. Technol. 2015, 261, 21-27. [CrossRef]

21. Okamoto, H.; Okamoto, H. Phase Diagrams for Binary Alloys; ASM International: Materials Park, OH, USA, 2000 ; Volume 44.

22. Hornbuckle, B.C.; Xiao, X.Y.; Noebe, R.D.; Martens, R.; Weaver, M.L.; Thompson, G.B. Hardening behavior and phase decomposition in very Ni-rich Nitinol alloys. Mater. Sci. Eng. A 2015, 639, 336-344. [CrossRef]

23. Khanlari, K.; Ramezani, M.; Kelly, P.; Cao, P.; Neitzert, T. Mechanical and microstructural characteristics of as-sintered and solutionized porous $60 \mathrm{NiTi}$. Intermetallics 2018, 100, 32-43. [CrossRef]

24. Feng, Y.; Du, Z.; Hu, Z. Study on the Effect of Ni Addition on the Microstructure and Properties of NiTi Alloy Coating on AISI 316 L Prepared by Laser Cladding. Materials 2021, 14, 4373. [CrossRef]

25. Du, Z.; Hu, Z.; Feng, Y.; Mo, F. The Effect of Powder Composition on the Microstructure and Corrosion Resistance of Laser Cladding 60NiTi Alloy Coatings on SS 316L. Metals 2021, 11, 1104. [CrossRef]

26. Zhou, S.; Xiong, Z.; Dai, X.; Liu, J.; Zhang, T.; Wang, C. Microstructure and oxidation resistance of cryomilled NiCrAlY coating by laser induction hybrid rapid cladding. Surf. Coat. Technol. 2014, 258, 943-949. [CrossRef]

27. Zhuang, Q.; Zhang, P.; Li, M.; Yan, H.; Yu, Z.; Lu, Q. Microstructure, Wear Resistance and Oxidation Behavior of Ni-Ti-Si Coatings Fabricated on $\mathrm{Ti}_{6} \mathrm{Al}_{4} \mathrm{~V}$ by Laser Cladding. Materials 2017, 10, 1248. [CrossRef]

28. Carvalho, P.A.; Vilar, R. Laser alloying of zine with aluminum: Solidification structure. Surf. Coat. Technol. 1997, 91, 158-166. [CrossRef]

29. Pouquet, J.; Miranda, R.M.; Quintino, L.; Williams, S. Dissimilar laser welding of NiTi to stainless steel. Int. J. Adv. Manuf. Technol. 2011, 61, 205-212. [CrossRef]

30. Bozzolo, G.; Noebe, R.D.; Mosca, H.O. Site preference of ternary alloying additions to NiTi: $\mathrm{Fe}, \mathrm{Pt}, \mathrm{Pd}, \mathrm{Au}, \mathrm{Al}, \mathrm{Cu}, \mathrm{Zr}$ and Hf. J Alloys Compd. 2005, 389, 80-94. [CrossRef]

31. Hu, Y.; Wang, Z.; Ai, J.; Bu, S.; Liu, H. Preparation of Coating on the Titanium Surface by Micro-Arc Oxidation to Improve Corrosion Resistance. Coatings 2021, 11, 230. [CrossRef]

32. Li, T.; Liu, L.; Zhang, B.; Li, Y.; Wang, F. An investigation on the continuous and uniform thin membrane passive film formed on sputtered nanocrystalline stainless steel. Corros. Sci. 2016, 104, 71-83. [CrossRef]

33. Robin, A.; Meirelis, J.P. Influence of fluoride concentration and $\mathrm{pH}$ on corrosion behavior of titanium in artificial saliva. J. Appl. Electrochem. 2007, 37, 511-517. [CrossRef]

34. Figueira, N.; Silva, T.M.; Carmezim, M.J.; Fernandes, J.C.S. Corrosion behaviour of NiTi alloy. Electrochim. Acta 2009, 54, 921-926. [CrossRef]

35. Wever, D.J.; Veldhuizen, A.G.; Vries, J.d.; Busscher, H.J.; Uges, D.R.A.; Horn, J.R.v. Electrochemical and surface characterization of a nickel-titanium alloy. Biomaterials 1998, 19, 761-769. [CrossRef]

36. Cheng, F.; Shi, P.; Man, H.C. A preliminary study of $\mathrm{TiO}_{2}$ deposition on NiTi by a hydrothermal method. Surf. Coat. Technol. 2004, 187, 26-32. [CrossRef]

37. Cheng, Y.; Cai, W.; Li, H.; Zheng, Y. Surface modification of NiTi alloy with tantalum to improve its biocompatibility and radiopacity. J. Mater. Sci. 2006, 41, 4961-4964. [CrossRef]

38. Shen, F.; Tao, W.; Li, L.; Zhou, Y.; Wang, W.; Wang, S. Effect of microstructure on the corrosion resistance of coatings by extreme high speed laser cladding. Appl. Surf. Sci. 2020, 517, 146085. [CrossRef]

39. Shokouhfar, M.; Allahkaram, S.R. Effect of incorporation of nanoparticles with different composition on wear and corrosion behavior of ceramic coatings developed on pure titanium by micro arc oxidation. Surf. Coat. Technol. 2017, 309, 767-778. [CrossRef]

40. Wang, Q.-Y.; Pei, R.; Liu, S.; Wang, S.-L.; Dong, L.-J.; Zhou, L.-J.; Xi, Y.-C.; Bai, S.-L. Microstructure and corrosion behavior of different clad zones in multi-track Ni-based laser-clad coating. Surf. Coat. Technol. 2020, 402, 126310. [CrossRef]

41. Olaseinde, O.A. Comparative Study of the Effect of Temperature on the Corrosion Behaviour of 2205 Duplex Stainless Steel and 316 Austenitic Stainless Steel in Acidic Chloride Environment. Adv. Mater. Phys. Chem. 2015, 5, 185. [CrossRef]

42. Stoynov, Z.; Grafov, B.; Savova-Stoynova, B.; Elkin, V. Electrochemical Impedance; Publishing House Science: Moscow, Russia, 1991.

43. Gaberšček, M.; Pejovnik, S. Impedance spectroscopy as a technique for studying the spontaneous passivation of metals in electrolytes. Electrochim. Acta 1996, 41, 1137-1142. [CrossRef]

44. Shi, Z.-P.; Wang, Z.-B.; Wang, J.-Q.; Qiao, Y.-X.; Chen, H.-N.; Xiong, T.-Y.; Zheng, Y.-G. Effect of Ni Interlayer on Cavitation Erosion Resistance of NiTi Cladding by Tungsten Inert Gas (TIG) Surfacing Process. Acta Metall. Sin. (Engl. Lett.) 2019, 33, 415-424. [CrossRef] 